\title{
Cardiac technology
}

\section{Pooja S. Jagadish}

Department of Internal Medicine, University of Tennessee Health Science Center, Memphis, TN, USA

Correspondence to: Pooja S. Jagadish. 956 Court Ave., Suite H314, Memphis, TN 38163, USA. Email: jagadish@uthsc.edu.

Submitted Jul 01, 2019. Accepted for publication Jul 12, 2019.

doi: $10.21037 / \mathrm{atm} .2019 .07 .88$

View this article at: http://dx.doi.org/10.21037/atm.2019.07.88

Cardiology has blossomed over many years

From 1948, when Framingham got cheers

For teaching us about the ways that doctors can prevent

Diseases of the heart and any cardiac event.

Or in 1929, when Forssmann stole supplies,

To demonstrate that catheters could revolutionize

A way to target therapies with ultimate control-

A pathway to the arteries that many called "too bold".

Imaging has taken cardiology by storm,

Now, echoes and CT scans are undoubtedly the norm.

Electrocardiography became another feat,

Heralding ablations to correct erratic beats.

Pharmacology has also made tremendous strides

Where anti-rhythm therapies have shadowed glycosides.

Aspirin has a role but trials recently cast doubt.

Newer anti-platelets are slowly breaking out.

As the field advances, we have witnessed this new trend-

Minimize intrusion to achieve a matching end.

With non-invasive monitors and fewer open hearts,

Curious are we to what the future will impart.

\section{Acknowledgments}

None.

\section{Footnote}

Conflicts of Interest: The author has no conflicts of interest to declare. 
Ethical Statement: The author is accountable for all aspects of the work in ensuring that questions related to the accuracy or integrity of any part of the work are appropriately investigated and resolved.

Cite this article as: Jagadish PS. Cardiac technology. Ann Transl Med 2019;7(17):423. doi: 10.21037/atm.2019.07.88 